\title{
TITANIUM MESH APLICATION ON ANTERIOR ALVEOLAR PROCESS AUGMENTATION PROCEDUR : A CASE REPORT
}

\section{Helmi Fathurrahman*, Rikko Hudyono**}

*Departemen Prosthodonsia Fakultas Kedokteran Gigi, Universitas Islam Sultan Agung Semarang

**Rumah Sakit Islam Gigi \& Mulut Sultan Agung

Correspondence : Helmi Fathurrahman, Departemen Prosthodonsia Fakultas Kedokteran Gigi, Universitas Islam Sultan Agung Semarang

Email : helmi f@unissula.ac.id

\begin{tabular}{|c|}
\hline Keywords: \\
Bone reconstruction, dental \\
implant, Titanium mesh
\end{tabular}

\begin{abstract}
Background: Bone reconstruction in a dental implant is a big challenge work, especially in a large defect where there was no anatomic supporting tissue. Nowadays there is no ideal membrane to be considered. In this case, titanium, even though second surgery is needed, seems the best choice as it can maintain its shape under the flap. Titanium may cause a membrane perforation on the mucosa in a thin gingival phenotype case.

Purpose: This case report aimed to present a bone reconstruction procedure using 3D titanium membranes for dental implant treatment. Case. A 37 years old male patient came to the clinic with a chief complaint was a defect on his anterior tooth. Intraoral examination revealed an 11 fractured and luxated.

Methode and Treatment Result: We used an allograft covered with 3D Titanium mesh after loading a dental implant. At the end of the surgery, a resorbable membrane was applied.

Conclusion: It is concluded that 3D Titanium mesh can be an application for anterior bone reconstruction.
\end{abstract}

\section{PENDAHULUAN}

Tatalaksanan kasus edentulous baik parsial maupun total salah satunya adalah dengan pemasangan implan gigi1. Keberhasilan pemasangan implan gigi dipengaruhi oleh kondisi prosesus alveolaris. Defisiensi prosesus alveolaris merupakan suatu masalah yang akan mempengaruhi daya tahan implan gigi².

Defisiensi prosesus alveolaris cenderung terjadi pada area di sekeliling implan saat pemasangan implan gigi segera setelah ekstraksi gigi. Kondisi ini akan mempengaruhi daya dukung prosesus alveolaris terhadap implan gigi. Pertumbuhan jaringan ikat di area ini akan mengurangi keberhasilan osseointegrasi ${ }^{3}$. Berdasarkan pola resorbsi, defisiensi prosesus alveolaris diklasifikasikan dalam 3 jenis yaitu horizontal, vertikal dan kombinasi antara keduanya ${ }^{4}$.

Solusi dari masalah tersebut adalah dengan melakukan augmentasi prosesus alveolaris $^{5}$. Salah satu metode augmentasi prosesus alveolaris addalah guided bone regeneration (GBR). Konsep GBR adalah aplikasi material bone graft yang dikombinasikan dengan suatu barier, baik itu resorbable atau nonresorbable ${ }^{6}$.

Aplikasi resorbable membrane memiliki kekurangan pertumbuhan prosesus alveolaris tidak terkontrol oleh operator, sehingga memiliki resiko kolaps dan invasi sel epitel pada daerah augmentasi. Non-resorbable membrane memiliki kelebihan bersifat kaku dan mencegah pertumbuhan epitel sehingga proses regenerasi lebih terkontrol oleh operator ${ }^{7}$. Salah satu non 
resorbable membrane adalah titanium mesh. Alat ini didesain untuk augmentasi prosesus alveolaris bukal atau labial. Kelebihan material ini adalah dapat terkoneksi dengan badan implan, mudah dipasang dan dilepas, serta membantu proses augmentasi prosesus alveolaris dalam bentuk 3 dimensi ${ }^{8}$.

Tujuan tulisan ini adalah untuk melakukan evaluasi terhadap aplikasi titanium mesh pada proses augmentasi prosesus alveolaris anterior guna mendukung pemasangan implan gigi.

\section{KASUS}

Seorang pasien laki-laki 37 tahun datang dengan keluhan penampilannya terganggu karena gigi depan kanan atas patah. Keluhan dirasakan sejak 2 minggu yang lalu. Pasien memiliki riwayat trauma gigi anterior akibat kecelakaan lalu-lintas. Pemeriksaan intra oral menunjukkan terdapat fraktur mahkota gigi 11 disertai luksasi derajat 3 dan kerusakan dinding labial

Rencana perawatan yang ditetapkan adalah pencabutan gigi 11 dan pemasangan implan gigi dengan metode immediate dental implan. Aplikasi membran titanium dengan material bone graft dilakukan guna mendukung rekonstruksi tulang bukal. Flap mukoperiosteal dibuat melewati labial gigi 11 (Gambar 1).

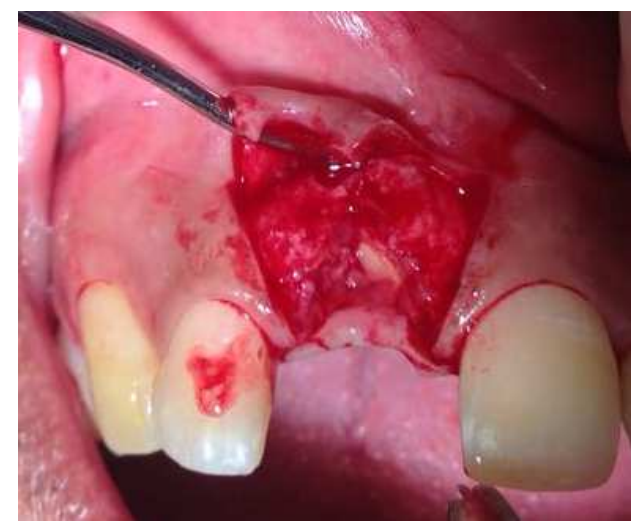

Gambar 1. Flap mukoperiosteal pada labial gigi 11
Kunjungan pertama pasien dilakukan pencabutan gigi 11 dengan metode atraumatik kemudian dilakukan prosedur osteotomi (Gambar 1) dilanjutkan dengan insersi implan gigi menggunakan rachet (Gambar 2). Setelah proses insersi implan dilaksanakan maka flat abutment dipasang pada permukaan badan implan (Anyone $4,5 \times 11.5 \mathrm{~mm}$ - Megagen). Material bone graft diaplikasikan pada daerah defek (SureOss $0.25 \mathrm{cc}$ - HanzMed Corp + Autogenous Bone), membran titanium dipasang menutupi badan implan dan daerah defek (iGen-Megagen) (Gambar 3a). Selanjutnya membrane kolagen (SuredermHanzMed Corp) dipasang menutupi membrane titanium beserta daerah defek. Cover screw dipasang menembus membran kolagen hingga terkoneksi dengan badan implan (Gambar 3b). Penutupan flap menggunakan benang resorbable PGA 4,0 dengan metode coronally repositioned flap dan dilakukan secara tension free (Gambar 4).

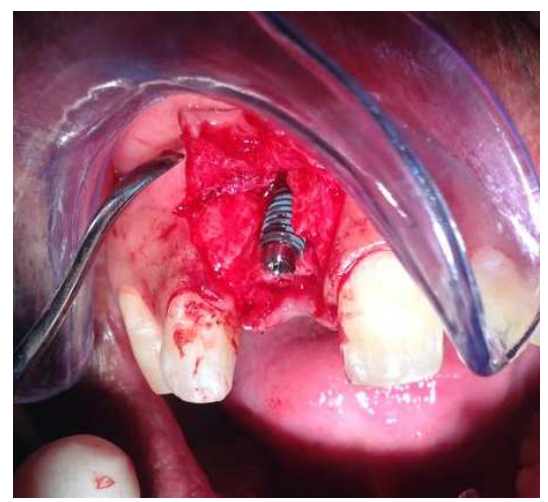

Gambar 2. Pemasangan implan gigi 11

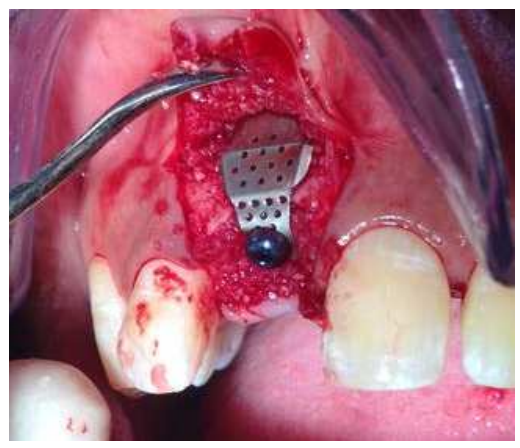

Gambar 3a. Aplikasi titanium mesh menutupi badan implan 


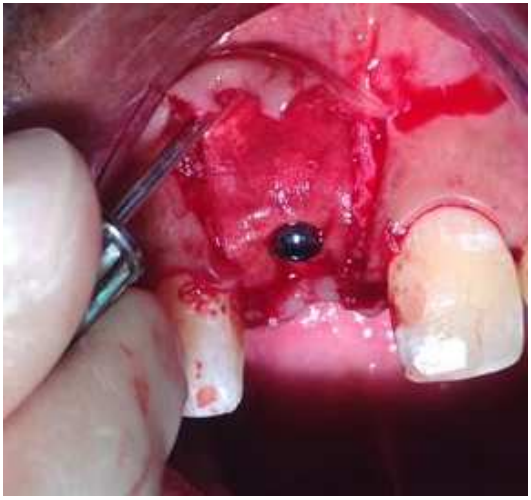

Gambar 3b. Aplikasi membran kolagen sebelum penjahitan flap

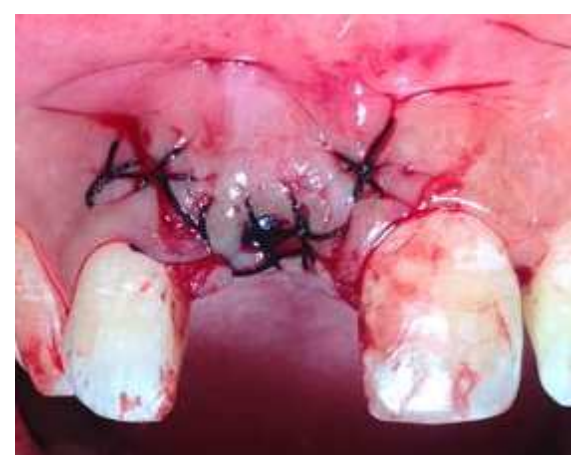

Gambar 4. Penjahitan flap

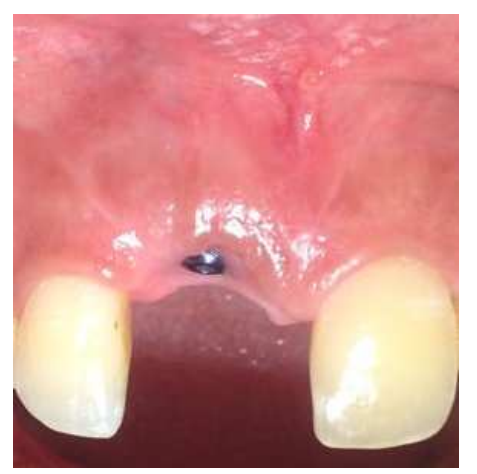

Gambar 5a. Evaluasi klinis 6 bulan post insersi implan

Evaluasi pasca osteotomi dilakukan pada $\mathrm{H}+7, \mathrm{H}+30, \mathrm{H}+90$, dan $\mathrm{H}+180$. Hasil pemeriksaan menunjukkan tidak terdapat pembengkakan, rasa nyeri, infeksi ataupun komplikasi poasca insersi implan gigi (Gambar 5a). Evaluasi $\mathrm{H}+180$ (6 bulan) rontgen menunjukkan pertumbuhan tulang yang baik disekitar implan, implan tampak terdukung oleh tulang (Gambar 5b). Kemudian dilakukan pembuatan flap dengan prosedur insisi area crestal. Coverscrew dilepas guna memberi akses pengangkatan membran titanium (Gambar 6). Selanjutnya dilakukan pemasangan healing abutment dan flap ditutup kembali dengan metode penjahitan pasif.

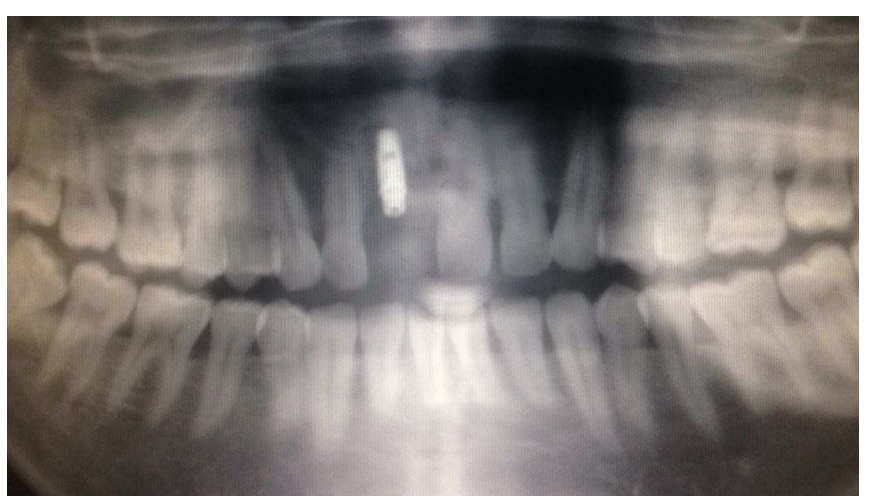

Gambar 5b. Hasil rontgen 6 bulan post insersi implan

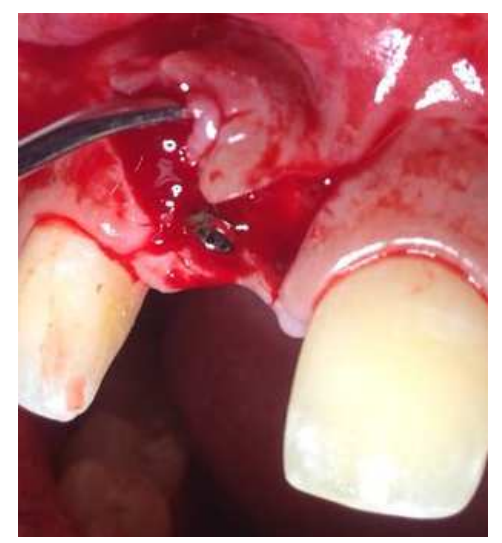

Gambar 6. Pembuatan flap area gigi 11 untuk aplikasi healing abutment

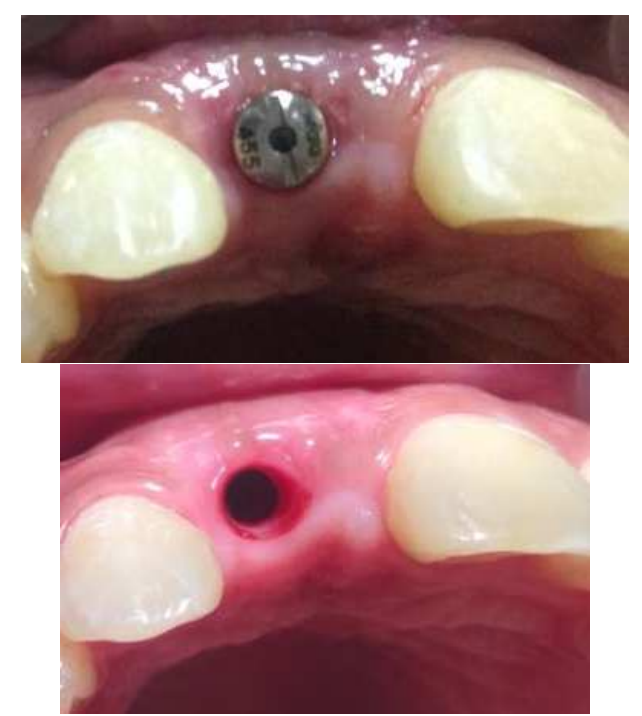

Gambar 7. Evaluasi klinis post insersi healing abutment 


\section{DISKUSI}

Hasil perawatan pada bulan ke 6 menunjukkan tidak terdapat nyeri, pembengkakan dan kemerahan pada daerah grafting. Ketebalan tulang palatal $2 \mathrm{~mm}$ dan terdapat pertumbuhan tulang bukal hingga ketebalan $2 \mathrm{~mm}$. Kondisi ini sesuai dengan teori bahwa salah satu tanda keberhasilan GBR adalah tidak terdapat tandatanda inflamasi ${ }^{1}$. Untuk mendapatkan stabilitas jaringan dan sustainibilitas implan gigi maka ketebalan tulang disekitar implan adalah $2 \mathrm{~mm}$ atau lebih ${ }^{9}$.

Pemeriksaan klinis setelah masa
penyembuhan menunjukkan tidak terdapat
mobilitas implan gigi. Hasil ini diidukung dengan pemeriksaan oleh pemeriksaan rontgen yang menunjukkan tidak ada gambaran radiolusen di sekeliling implang serta terdapat ketebalan tulang yang adekuat di mesial dan distal. Stabilitas implan adalah salah satu kunci keberhasilan pemasangan implan gigi. Apabila setelah melewati fase penyembuhan implan gigi mengalami luksasi maka dapat dipastikan terjadi kegagalan osteointegrasi ${ }^{10}$.

Evaluasi pasca pemasangan implan gigi disertai GBR menunjukkan tidak terdapat eksposur titanium mesh, gusi tampak estetis dan tidak kolaps. Eksposur membran adalah salah satu resiko pada prosedur augmentasi prosesus alveolaris ${ }^{11}$. Kondisi penyembuhan luka tanpa eksposur membran akan meningkatkan pertumbuhan tulang hingga $74 \%$ lebih baik $^{12}$. Aplikasi titanium mesh dengan indikasi dan teknik yang tepat dapat mencegah eksposur membran dan kolapsnya daerah grafting. Indikasi penggunaan titanium mesh adalah augmentasi prosesus alveolaris dengan ukuran kecil dan sedang ${ }^{13}$. Titanium mesh paling tepat diaplikasikan pada gingiva dengan biotype tebal, apabila kondisi biotype tipis maka diperlukan lapisan tambahan menggunakan graft jaringan ikat atau membran platelet rich fibrin (PRF). Faktor lain yang mendukung tercapainya penyembuhan jaringan lunak yang estetis dan mencegah eksposur membran adalah penjahitan flap dengan teknik tension free ${ }^{14}$.

Kriteria membran yang ideal adalah : biokompatibel, mencegah penetrasi sel-sel yang tidak diinginkan, menjaga daerah pertumbuhan prosesus alveolaris, serta mudah diaplikasikan ${ }^{15}$. Titanuim mesh memiliki biokompatibilitas yang baik, hal ini dibuktikan dengan kemampuannya berintegrasi dengan gingiva. Material ini mencegah pertumbuhan jaringan ikat pada daerah grafting ${ }^{16}$. Struktur titanium mesh yang kaku berfungsi menjaga daerah pertumbuhan prosesus alveolaris dari tekanan eksternal ${ }^{17}$. Stabilitas titanium mesh didapatkan dari kemampuannya untuk disatukan dengan badan implan, hal ini mendukung angiogenesis dan pertumbuhan sel. Keunggulan lain titanium mesh adalah mudah diaplikasikan dan diadaptasikan pada daerah defect karena memiliki variasi bentuk dan ukuran ${ }^{18}$.

\section{KESIMPULAN}

Titanium mesh dapat diaplikasikan dalam rekonstruksi tulang labial pada pemasangan implan gigi anterior.

\section{DAFTAR PUSTAKA}

1. Resnik. R.R., Misch's Contemporary Implant Dentistry, 4th Ed, 2020, Elsevier, Missouri.

2. Pagni. G., Pellegrini. G., Giannobile. W.V., dan Rasperini. G., Postextraction Alveolar Ridge Preservation: Biological Basis Nad Treatment. Int J. Dent., 2012;2012,1-13

3. Bassir. S.H., Kholy. K.E., Chen. C.U., Lee. K.H., dan Intini. G., Outcome of Early Dental Implant Placement Versus Other Dental Implant Placement Protocol: A systematic Review Nad Meta-analysis, J. Periodontol, 2019;90(5): :493-506

4. Kalsi. A.S., Kalsi. J.S., dan Bassi. S., Alveolar Ridge Preservation: Why, When and How, British Dental Journal, 2019; 227(4):264-274

5. Atieh. M.A., Alsabeeha. N.H.M., Payne. A.G., Duncan. W., Faggion. C.M., dan Esposito. M., 
Interventions for Replacing missing Teeth: Alveolar Ridge Preservation Techniques For Dental Implant Sites Development, Cochrane Database Syst Rev. 2015; 2015(5): 1-57

6. Elgali. I., Omar. O., Dahlin. C., dan Thomsen. P., Guided Bone Regeneration: Material and Biological Mechanism Revisited, Eur.J.Oral Sci., 2017, 125: 315-337

7. Her. S., Kang. T., dan Fien. M.J., titanium mesh as an alternative to a membrane for ridge augmentation, J. Oral Maxillofact Surg, 2012, $70: 803-810$

8. Rachmatia. Y.D., Ayukawa. Y., Furuhashi. A., dan Koyano. K., current barrier membranes: titanium mesh and other membranes for guided bone regeneration in dental aplications, J. Prosthodont Res., 2013, 57(1) : 3-14

9. Johnson. T.B., Siderits. B., Nye. S., Jeong. YH., Han. S-E., Rhyu. I-C., Han. J-S., Deguchy. T., Beck. F.M., dan Kim. D.G., Effect Of Guided Bone Regeneration on Bone Quality Surrounding Dental Implants. J. Biomech., 2019, 80: 166-170

10. French. D., Grandin. H.M., dan Ofec. R., Retrospective Cohort Study Of 4,591 Dental Implants: Analysis Of Risk Indicator For Bone Loss and Prevalence Of Peri-implant Mucositis and Peri-implantitis. J. Periodontol., 2019, 90(7): 691-700

11. Korzinskas. T., Jung. O., Smeets. R., Stojanovic. S., Najman. S., Glenske. K., Hahn. M., Wenisch. S., Schnettler. R., dan Barbeck. M., In Vivo Analysis of The Biocompatibility and Macrophage Response of A NonResorbable PTFE Membrane For Guided Bone Regeneration. 2018, Int. J. Mol.Sci., 19(10):1-12

12. Garcia. J., Dodge. A., Luepke. P., Wang. H-L., Kapila. Y., dan Lin. G.H., Effect of membrane e exposure on guided bone regeneration: $A$ systematic review and meta analysis. Clin. Oral Impl. Res., 2018, 00:1-11

13. Khojasteh. A., Soheilifar. S., Mohajerani. H., dan Nowzari. H., The effectiveness of barrier membranes on bone regeneration in localized bony defects: A systematic review. Int J Oral Maxillofac Implans, 2013, 28(4):1076-1089

14. Sakr. A.A., Shaaban. A.M., dan Elsheikh. S.A., Evaluation of the effect of I-Gen Titanium Membrane around immediate dental implans replacing posterior mandibular tooth with buccal bone defect, Alexandria Dental Journal, 2017, 42: 85-91

15. Bottino. M.C., Thomas. V., dan Schmidt. G., Recent advances in the development of GTR/GBR membranes for periodontal regeneration-a material perspective, Dental materials, 2012, 28(7): 703-721

16. Rachmatia. Y.D., Ayukawa. Y., Furuhashi. A., dan Koyano. K., Current barrier membranes: titanium mesh and other membranes for guided bone regeneration in dental aplications, Journal Of Prosthodontics Research, 2013, 57(1): 3-14

17. Gluckman. H., dan Toif, J.D., Guiden Bone Regeneration Using A Titanium Membrane At Implan Placement: A case Report and Literature Discussion, international dentistryafrican edition, 2014, 4(6): 20-29

18. Jung. G.U., Jeon. J.Y., Hwang. K.G., dan Park. C.J., Preliminary evaluation of threedimensional, costumized, and preformed titanium mesh in peri-implan alveolar bone regeneration, Journal of the Korean association of oral and maxillofacial surgeon, 2014, 40(4): 181-187 